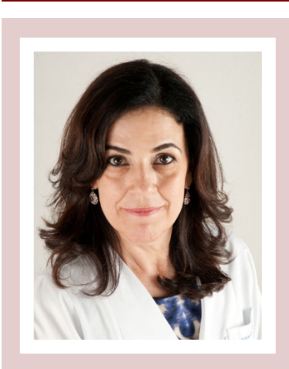

Samira Saady Morhy

Presidente do Departamento de Imagem Cardiovascular - SBC

Biênio 2016-2017

\section{Caros Sócios,}

É com muita alegria e entusiasmo que assumo a Presidência do Departamento de Imagem Cardiovascular (DIC) pelos próximos dois anos.

Após quatro anos participando ativamente da Diretoria do DIC (dois anos como Diretora Administrativa na Presidência do Dr. Jorge Assef, e mais dois anos como Vice-Presidente de Ecocardiografia na Presidência do Dr. Arnaldo Rabischoffsky), me sinto preparada para assumir este cargo.

Juntamente aos outros diretores (Silvio Barberato (PR) como Diretor Administrativo; Henry Abensur (SP) como Diretor Financeiro; Marcelo Campos Vieira (SP) como Vice-Presidente de Ecocardiografia; Lilian Paula (MG) como Vice-Presidente de Vascular; Tiago Senra (SP) como Vice-Presidente de Tomografia; Clério Azevedo (RJ) como Vice-Presidente de Ressonância; Gabriel Grossman (RS) como Vice-Presidente de Cardiologia Nuclear; Jose M. Del Castillo (PE) como Editor da Revista ABC- Imagem; Claudia G. Monaco (SP) como Coordenadora da Comissão de Habilitação; e Fabio Villaça Guimarães (SP) como Presidente do Conselho Deliberativo), teremos grandes desafios nesta empreitada.

Nossa meta principal é, além de dar continuidade aos trabalhos iniciados pelas outras Diretorias, a de nos aproximarmos mais das necessidades dos sócios, mediante mais programas educativos, mais suporte para aprimorar qualidade e excelência de atendimento, e de nos fazermos representar perante a sociedade, neste difícil cenário politico e financeiro atual do nosso país.

Para isso, vamos precisar da participação de todos vocês, enviando-nos suas opiniões e necessidades, utilizando nosso Portal (Contato e Fórum - Fale com o Presidente), ou pelos nossos telefones (11) 3259-2988 / (11) 3120-3363.

Contem conosco!

Abraços,

Samira Saady Morhy 